\title{
Covid-19 Induced Diabetes: Disclosing Truth behind the Potential Attention Seeker
}

\author{
Prathiba Annam, Kiranmai Mandava*, Anusha Manda, Avinash Kadam, Sneha Thakur \\ Department of Pharmacy Practice, St. Pauls College of Pharmacy, Hyderabad, Telangana, INDIA.
}

\begin{abstract}
Severe Acute Respiratory Syndrome Corona Virus-2 (SARS-CoV-2), the zoonotic virus answerable for the current global health crisis is ringing its dangerous bells on its post disease status. COVID-19 is causing multiple organ damage probably with its entry site. Insulin-Dependent Diabetes (IDDM) also known as Type I Diabetes is a multifactorial disease that typically occurs as a result of the interaction of genetic, environmental and immunologic factors. The mechanisms behind the development of Diabetes and associated consequences are complicated. The morphological mass of Insulin producing $\beta$-cells in the pancreatic islets of Langerhans and the functional status determine plasma Insulin levels. Insufficient Insulin levels may develop as a result of a lack of $\beta$-cell function resulting in hyperglycemia and Diabetes. Angiotensin-Converting Enzyme 2 (ACE2) receptor, the binding agent which allows Corona virus to enter and migrate to various organs such as lungs, heart, liver, pancreas, and kidneys is assumed to be responsible for this damage. The over expression of ACE2 receptor on pancreatic endocrine cells paves a way for extensive damage to Islets of Langerhans causing Insulin resistance and deficiency. Another common assumption among the researchers and health care professionals are the
\end{abstract}

dreadful relationship shared by viruses and Diabetes which can exacerbate or provoke autoimmunity leading to $\beta$-cell auto-oxidation. The metabolic complications like Diabetic Ketoacidosis (DKA) and Hyper osmolar hyperglycemia are predominantly seen in various regions of the world in people with Pre-Diabetes and non-diabetics. However, this review explored the probable truth behind COVID-19 induced new-onset Diabetes mellitus and its complications

Key words: COVID -19, Type-1 Diabetes, ACE2 receptor, Diabetic, Ketoacidosis.

Correspondence

Dr. Kiranmai Mandava,

Department of Pharmacy practice, St. Pauls College of Pharmacy, Hyderabad-501510, Telangana, INDIA.

Email id: drkiranmaim@stpaulscollege.ac.in

DOI: 10.5530/jyp.2021.13.88

\section{INTRODUCTION}

The COVID-19 pandemic has been wreaking havoc on the world for the past year and a half, with heart rending morbidity and mortality rates. The virus that caused the corona virus disease pandemic of 2019 (COVID-19) is the severe acute respiratory syndrome coronavirus-2 (SARS-CoV-2). ${ }^{1}$ Infection with SARS-CoV-2causes a large range of symptoms, including moderate acute respiratory sickness, respiratory failure, acute respiratory distress syndrome, and septic shock. ${ }^{2,3}$ The Angiotensin Converting Enzyme-2 (ACE2) receptor located in several human organs acts as a barricade allowing SARS-CoV-2 into host cells. ${ }^{4}$ Despite acting as an entry gate to viral particles, ACE2 hydrolyses angiotensin-II to angiotensin (I-VII) aid in counteracting the deleterious effects of the Renin - Angiotensin System (RAS) and exerts antiinflammatory actions. Various studies have been reported that SARSCoV-2 infection could down regulate ACE2 expression on cells, thereby disrupting the physiological balance between ACE2 and Angiotensin subsets. ${ }^{5}$ Excessive expression of cytokines and chemokines, insufficient interferon response, excessive recruitment of inflammatory cells and possible auto-antibody production are all thought to be significant considerations in disease pathogenesis induced by viruses. ${ }^{6}$ Plasma levels of pro-inflammatory cytokines (PICs) and chemokines, such as interleukins (IL-1, IL-6, IL-8, IL-12), Interferon-gamma-inducible protein 10 (IP-10) and monocyte chemoattractant protein-1 (MCP-1) are much higher in SARS infected patients. ${ }^{7,8}$ Severe disease is more common in older people and people who have underlying medical conditions such as Hypertension, Diabetes, Cardiovascular disease, Chronic lung disease, Cancer and Chronic kidney disease. ${ }^{9}$
Diabetes is considered as one of the essential risk factors for both kinds of Severe Acute Respiratory Syndrome Corona virus infection (SARS-CoV-1 and SARS-CoV-2). ${ }^{4}$ Epidemiological studies indicate that the Diabetes is the second common co-morbidity in COVID-19..$^{4,10}$ Uncontrolled glucose levels directly or indirectly impact the increased hospitalizations and mortality, especially during these pandemic conditions. It is repeatedly observed these days that COVID-19 and Diabetes are playing a mutual role in devastating the health conditions resulting to be a fatal one by inducing severe metabolic decompositions in Pre-Diabetic and people with new-onset Diabetes. Much pathology is assumed to be the reason for new-onset Diabetes caused by SARS-CoV-2 in the previously non-diabetic populations. ${ }^{11}$

Type 1 Diabetes (T1D) is an autoimmune illness that causes the Insulin producing cells in the pancreatic islets of Langerhans to malfunction and/or dies. ${ }^{12-16}$ The Insulin Dependent Diabetes Mellitus (IDDM) is more common in children, although it can also affect adults. ${ }^{17}$ The classic onset trio of signs and symptoms associated with type 1 Diabetes are polydipsia, polyphagia, and polyuria along with hyperglycemia remain as diagnostic hallmarks of Type I Diabetes mellitus. ${ }^{18-20}$ Environmental factors play a major role in the onset of IDDM which further on interaction with predisposing genes may induce an autoimmune attack on $\beta$-cells of the pancreas. ${ }^{1,4}$ The $\beta$-cell mass and function predominantly play a significant role in estimating plasma insulin levels. Insulin resistance or deficiency caused by impaired $\beta$-cell function or insufficient $\beta$-cell count respectively may result in hyperglycemia, further leading to Diabetes. ${ }^{12}$ The Type 1 Diabetes is characterized histologically by an immune

This is an open access article distributed under the terms of the Creative Commons Attribution-NonCommercial-ShareAlike 4.0 License, which allows others to remix, tweak, and build upon the work non-commercially, as long as the author is credited and the new creations are licensed under the identical terms. 
infiltrate containing significant numbers of mononuclear cells and CD8+ T lymphocytes within or around the pancreatic islets (Insulitis). CD8+ T cells appear to predominate, but the proportion of CD4+ and $\mathrm{CD} 8+\mathrm{T}$ cells, as well as the importance of other cell types in the infiltrate (e.g., Natural Killer Cells (NKC), Macrophages and Dendritic cells) are unknown. ${ }^{21}$ The Morphological approaches reveal a significant loss in $\beta$-cells over the time indicating a chronic autoimmune inflammation triggered by macrophages and lymphocytes that surround and infiltrate the islets. ${ }^{22,23}$ The $\beta$-cell autoimmunity is generally acknowledged as a chronic inflammatory response defined by the gradual infiltration of numerous immune effectors into the pancreatic islets. ${ }^{24,25}$ The autoimmune response of IDDM is aggravated by a significant genetic link among particular human leukocyte antigen haplotypes, as well as many variants of genes expressed by $\beta$-cells, T cells and other immune effectors $^{26-32} \beta$-cells expressing Human Leukocyte Antigen (HLA) class I antigens including peptides from one or more major autoantigens or environmental triggers (e.g., viruses) are hypothesized to be identified by specialized cytotoxic $\mathrm{CD} 8+\mathrm{T}$ lymphocytes and targeted for destruction. ${ }^{1,4,21}$

Transforming its face, the novel Corona virus continued to be at its peak concentration in various countries by rapidly spreading through symptomatic and asymptomatic transmitters. Despite its direct effects on defeating human health, it is also involved in causing multiple organ damage with unknown pathology. ${ }^{10}$ Having a bi-directional link between SARS-CoV-2 infection and poor glycemic control in Pre-Diabetes, hyperglycemia is digging the routes for increased hospitalizations, morbidity and mortality (Figure 1).

\section{PATHOLOGICAL COMPLICATIONS INDUCED BY COVID 19 INFECTION- DIABETES, KETOACIDOSIS AND OTHER IMPAIRED FUNCTIONS}

The exact pathophysiology behind new-onset Diabetes among COVID-19 patients is not yet known..$^{33}$ Assumptions were made based on the relationship (Figure 2) shared by viruses with Diabetes, the multi organ functional nature of the ACE2 receptor (which is said to be the entry point of SARS-CoV-2) and the $\beta$-cells autoimmune response towards inflammatory mediators. ${ }^{11}$

\section{VIRAL INFECTION AND PANCREATIC B-CELLS}

It is known for decades that viral infections and Type-1 Diabetes are very much correlated in their pathogenesis. The viruses commonly involved

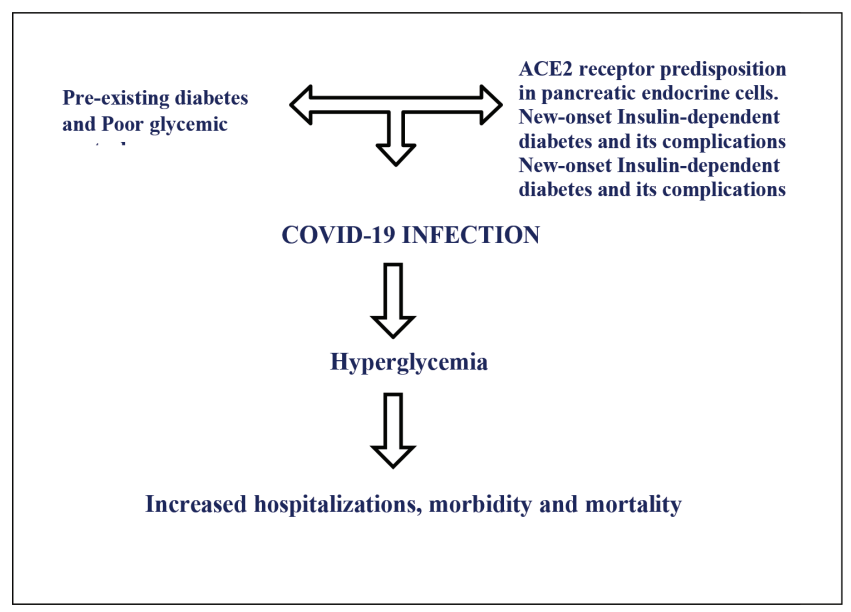

Figure 1: Bi-Directional Link between Covid-19 and Diabetes.

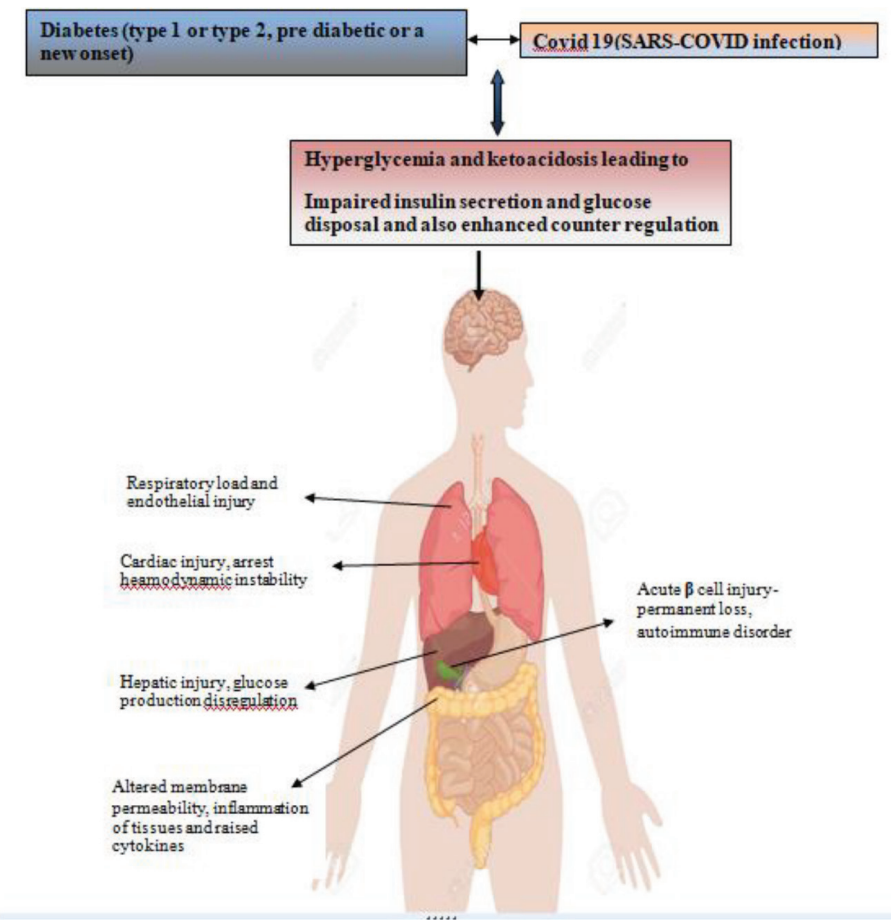

Figure 2: Pathogenesis of Covid-19 Induced Diabetes and ketoacidosis.

in inducing T1D are Enteroviruses (EVs), particularly Cox Sackievirus $B$ (CVBs). The other viruses which can also cause the development of IDDM are Mumps, Rubella, Cytomegalovirus, Epstein-Barr virus, Rotavirus. ${ }^{13,16,24,34-38}$ In theory, virus-induced beta-cell damage is caused by either direct lytic effects of viral replication or damage mediated by auto reactive $\mathrm{CD} 4+\mathrm{T}$ cells in response to the host inflammatory response, resulting in auto immunity. While direct viral infection destroys more than $90 \%$ of $\beta$-cells, limited lysis releases Islet cell antigens, ${ }^{19-22}$ which in conjunction with an augmented immune response leads to autoimmunity. ${ }^{29-32}$

Autoimmune generation is thought to be the plausible explanation for the obliteration of $\beta$-cells in the Islets of Langerhans, resulting in low insulin levels and increased glucose levels. Interconnection between SARS-CoV and Diabetes is analyzed in various studies. From the insights of the 2003 pandemic, hyperglycemia was noted as a predictor of morbidity and mortality. ${ }^{18}$ Increased glucose levels are detected in mildly infected patients who are not on corticosteroids reflecting a thought shift to the destruction of $\beta$-cells hypothesis. ${ }^{43}$ A study conducted in 2017 named The Environmental Determinants of Diabetes in the Young (TEDDY) reported that 87,327 patients with a recent respiratory (upper and lower) tract infection were at high risk of developing $\beta$-cell autoimmunity. The Corona viruses were detected as one of the pathogens responsible for the infection caused among the subjects enrolled in the study. ${ }^{24}$ Pancreatic $\beta$-cell annihilation concerning viral diseases can be clarified through different components. The amplification cycle of the virus and/ or diffusion of viral antigens through course may straightforwardly bring about loss of $\beta$-cells deciding a forceful immune assault involving surrounding pancreatic cells. ${ }^{25-28}$ Damage to $\beta$-cells may result in the release of islet antigens expressed by antigen-presenting cells in regional lymph nodes. Over expression of the major histocompatibility complex (Class-I) protein could be the reason for the $\beta$-cell epitope's prolonged exposure to the immune system, especially in chronic infection situations, allowing for an increased chance of auto-antibody formation. Cross-reactive antibody production against $\beta$-cells can be observed even after complete clearance of viral infection through the similar 
homologies shared among viral epitopes and amino acid sequences of auto antigens. Predominantly, the release of cytokines and activation of T-cells can contribute to an insulin-dependent Diabetes mellitus through a viral infection generally in individuals predisposed to autoimmunity genetically. ${ }^{26}$

\section{SARS-COV-2 AND ANGIOTENSIN-CONVERTING ENZYME 2 (ACE2)}

Angiotensin-Converting Enzyme 2 (ACE2) is thought to be the novel corona virus major binding receptor for causing multisystem damage, and a recent study confirmed that SARS-CoV-2 uses ACE2 as a functional binding receptor. ${ }^{27,28} \mathrm{ACE} 2$ is primarily linked to cell membranes and is only rarely seen in a soluble form in the circulation. The breakdown of Angiotensin II to angiotensin1-7 is a major beneficial activity of membrane-bound and soluble ACE2. As a result, ACE2 receptors restrict several deleterious effects caused by Angiotensin II binding to AT1 receptors, including vasoconstriction, increased inflammation, and thrombosis. ${ }^{29}$ The ACE-2 receptor is part of the RAS's dual system, which includes the ACE-Ang-II-AT1R axis and the ACE-2-Ang-(1-7)-Mas axis. The ACE-Ang-II-AT1R axis is known to be upregulated in metabolic diseases and with increasing age, while the ACE-2-Ang-(1-7) Mas axis is down regulated. In the respiratory system, the activated ACE-Ang-II$A T 1 R$ axis causes pro-inflammatory and pro-fibrotic effects. It also has the ability to cause vascular dysfunction, cardiac fibrosis, nephropathy, and insulin secretory abnormalities with enhanced insulin resistance upon activation. Initially, it is determined that ACE2 was located abundantly in the small intestine and epithelia of the lungs from all the fifteen homes (organs) in humans. Later, a study conducted on 72 human tissues by harmer and his co-investigators confirmed lung parenchyma, bronchus, ileus, testis, renal, cardiovascular, and gastrointestinal tissues along with pancreas where ACE2 mRNA expression was observed. ${ }^{31}$ Twenty out of thirty nine patients with an average age of $47.2 \pm 2$ years had developed Type-1 Diabetes during their hospital tenure. Only two patients out of six who were discharged with new onset insulin-dependent Diabetes had active Diabetes following a three-year follow-up, indicating that this new-onset Diabetes is transient and may not be lasting. ${ }^{32}$

Various autopsy studies performed to analyze the multi-organ effect of SARS-COVID-19 on patients who faced death due to infection demonstrated few atypical pathology changes which may have contributed to the mortality. ${ }^{33-35}$ Fatty degeneration, hydropic degeneration, and interstitial cell proliferation in the heart, liver, pancreas, and kidney were the pathological variations mentioned in those studies. ${ }^{36}$ According to a recent study focusing on evaluating pancreatic lesions pathogenesis and glucose intolerance in SARS patients, SARS-CoV can damage several organs, including the lungs, kidneys, heart, and pancreas (particularly the endocrine component). This study also suggested SARS-CoV may cause Acute Type-1 Diabetes relating to its damage on Islets of Langerhans and its abundant expression on endocrine tissues than the exocrine part of the pancreas. ${ }^{37}$

Despite studies demonstrating the independence between corticosteroid administration and hyperglycemia in new-onset Diabetes in active and/ or post COVID-19 patients, hyperglycemia is one of the most commonly seen side effects of glucocorticoids treatment. ${ }^{43}$ Irrespective of the actual pathway leading to high glucose levels in a non-diabetic person, COVID-19 is the building of its blocks by increasing hospitalizations and mortalities (Figure 2).

\section{COVID-19 AND DIABETIC KETOACIDOSIS (DKA)}

COVID-19 patients with pre-existing Diabetes, particularly those with poor glycemic control, had severe metabolic consequences such as Diabetic Ketoacidosis (DKA) and Hyperosmolarity. ${ }^{38-47}$ Diabetic ketoacidosis is the most common hyperglycemic crisis involving hyper osmolar hyperglycemia and hyper osmolar ketoacidosis. ${ }^{44}$ Deficiency of insulin and insulin resistance caused by viral mechanisms may precipitate ketosis due to impaired glucose use. While there isn't enough data to determine the relation between new-onset DKA and COVID-19, few studies have explored the potential. According to a cohort study, 42 of 658 hospitalized patients with an active COVID-19 infection (mean age: 57.5 years) developed ketosis. Only one of the two active instances of newly formed DKA reported by Nadine and her colleagues had a previous history of Diabetes. ${ }^{45}$ According to report by Kulachanya Suwanwongse and Nehad Shabarek 2021, around 15\% of patients with active COVID-19 infection and pre-existing Diabetic Mellitus developed DKA, with a 50 percent fatality risk. They also documented three cases of previously non-diabetic patients developing new-onset DKA, two of whom had a family history of Diabetes. ${ }^{33}$

\section{Take Home Message For Researchers And Physicians}

Regular monitoring of blood glucose levels and esteemed observation of signs and symptoms of Diabetes and its metabolic complications like DKA is very much necessary to avoid end-stage mortality and morbidity. Further studies should be implicated in exploring the prevention and management patterns of new-onset Diabetes caused by the novel corona virus. The puzzle behind these complications, caused by COVID-19 should be solved as soon as possible which can aid in designing treatment guidelines based on condition and severity. Continuous education of all healthcare professionals regarding day-to-day complications cost by SARS-CoV-2 will help in the betterment of patient care.

\section{CONCLUSION}

SARS-CoV-2, the virus that causes COVID-19, has a significant influence on worldwide health. Despite COVID-19's specific diseasecausing activities, SARS-CoV-2 is also causing a slew of opportunistic infections and complications, all of which worsen the prognosis. Insulin insufficiency and resistance are thought to be associated with SARS$\mathrm{CoV}-2$ pathogenesis causing vulnerable complications such as Diabetes and diabetic ketoacidosis. The pathological reason behind this mystery is assumed to be the ACE2 receptor serving as the virus's entry point, beta-cell autoimmunity, and the deadly relation between the virus and Diabetes. But there are not many studies proving this theoretical pathophysiology leading to suppressed insulin levels and increased risk of new-onset Diabetes and its complications. Future research should focus on elucidating the pathogenesis of SARS-CoV-2 that leads to these unique consequences and a poorer prognosis.

\section{CONFLICT OF INTEREST}

The authors declare no conflicts of interest.

\section{ACKNOWLEDGEMENT}

The authors are thankful to the Management, St. Pauls College of Pharmacy for providing the access and facilities to carry out the study.

\section{REFERENCES}

1. Shanmugam C, Mohammed AR, Ravuri S, Luthra V, Rajagopal N, Karre S. COVID-2019 - A comprehensive pathology insight. Pathol Res Pract. 2020;216(10):153222. doi: 10.1016/j.prp.2020.153222.

2. Rothan HA, Byrareddy SN. The epidemiology and pathogenesis of corona virus disease (COVID-19) outbreak. J Autoimmun. 2020;109:102433. doi: 10.1016/j. jaut.2020.102433.

3. Huang C, Wang Y, Li X, Ren L, Zhao J, Hu Y, et al. Clinical features of patients infected with 2019 novel coronavirus in Wuhan, China. Lancet. 2020 Feb 15;395(10223):497-506. doi: 10.1016/S0140-6736(20)30183-5.

4. Bornstein SR, Rubino F, Khunti K, Mingrone G, Hopkins D, Birkenfeld AL, et al. 
Practical recommendations for the management of diabetes in patients with COVID-19. Lancet Diabetes Endocrinol. 2020;8(6):546-50. doi: 10.1016/S22138587(20)30152-2, PMID 32334646

5. Ni W, Yang X, Yang D, Bao J, Li R, Xiao Y, et al. Role of angiotensin-converting enzyme 2 (ACE2) in COVID-19. Crit Care. 2020;24(1):422. doi: 10.1186/s13054020-03120-0, PMID 32660650

6. Wong CK, Lam CW, Wu AK, IpWK, Lee NL, Chan IH, et al. Plasma inflammatory cytokines and chemokines in severe acute respiratory syndrome. Clin Exp Immunol. 2004;136(1):95-103. doi: 10.1111/j.1365-2249.2004.02415.x, PMID 15030519

7. Zhang Y, Li J, Zhan Y, Wu L, Yu X, Zhang W, et al. Analysis of serum cytokines in patients with severe acute respiratory syndrome. Infect Immun. 2004;72(8):4410-5. doi: 10.1128/IAI.72.8.4410-4415.2004, PMID 15271897, PMCID PMC470699.

8. Jain V, Yuan JM. Predictive symptoms and comorbidities for severe COVID-19 and intensive care unit admission: A systematic review and meta-analysis. Int J Public Health. 2020;65(5):533-46. doi: 10.1007/s00038-020-01390-7, PMID 32451563, PMCID PMC7246302.

9. Caruso $\mathrm{P}$, Longo $\mathrm{M}$, Esposito $\mathrm{K}$, Maiorino Ml. Type 1 diabetes triggered by covid-19 pandemic: A potential outbreak? Diabetes Res Clin Pract. 2020;164:108219. doi: 10.1016/j.diabres.2020.108219.

10. Boddu SK, Aurangabadkar G, Kuchay MS. New onset diabetes, type 1 diabetes and COVID-19. Diabetes Metab Syndr. 2020;14(6):2211-17. doi: 10.1016/j. dsx.2020.11.012, PMID 33395782.

11. Op de Beeck A, Eizirik DL. Viral infections in type 1 diabetes mellitus--why the $\beta$ cells? Nat Rev Endocrinol. 2016;12(5):263-73. doi: 10.1038/nrendo.2016.30, PMID 27020257, PMCID PMC5348720.

12. Chen C, Cohrs CM, Stertmann J, Bozsak R, Speier S. Human beta cell mass and function in diabetes: Recent advances in knowledge and technologies to understand disease pathogenesis. Mol Metab. 2017;6(9):943-57. doi: 10.1016/j. molmet.2017.06.019, PMID 28951820.

13. Anderson MS, Bluestone JA. The NOD mouse: A model of immune dysregulation. Annu Rev Immunol. 2005;23:447-85. doi: 10.1146/annurev. immunol.23.021704.115643, PMID 15771578.

14. Atkinson MA, Eisenbarth GS, Michels AW. Type 1 diabetes. Lancet. 2014;383(9911):69-82. doi: 10.1016/S0140-6736(13)60591-7.

15. Cooke DW, Plotnick L. Type 1 diabetes mellitus in pediatrics. Pediatr Rev. 2008;29(11):374-84; quiz 385. doi: 10.1542/pir.29-11-374, PMID 18977856

16. Shapiro AM, Lakey JR, Ryan EA, Korbutt GS, Toth E, Warnock GL, et al. Islet transplantation in seven patients with type 1 diabetes mellitus using a glucocorticoid-free immunosuppressive regimen. N Engl J Med. $2000 \mathrm{Jul}$ 27;343(4):230-8. doi: 10.1056/NEJM200007273430401, PMID 10911004.

17. Morahan G, Huang D, Ymer SI, Cancilla MR, Stephen K, Dabadghao P, et al. Linkage disequilibrium of a type 1 diabetes susceptibility locus with a regulatory IL12B allele. Nat Genet. 2001 Feb;27(2):218-21. doi: 10.1038/84872. Erratum in: Nat Genet. 2001;27(2):218-21. doi: 10.1038/84872, PMID 11175794.

18. Booth CM, Matukas LM, Tomlinson GA, Rachlis AR, Rose DB, Dwosh HA et al. Clinical features and short-term outcomes of 144 patients with SARS in the greater Toronto area. JAMA. 2003;289(21):2801-9. doi: 10.1001/jama.289.21. JOC30885, PMID 12734147.

19. Allard R, Leclerc P, Tremblay C, Tannenbaum TN. Diabetes and the severity of pandemic influenza A (H1N1) infection. Diabetes Care. 2010;33(7):1491-3. doi: 10.2337/dc09-2215, PMID 20587722.

20. Yang JK, Lin SS, Ji XJ, Guo LM. Binding of SARS coronavirus to its receptor damages islets and causes acute diabetes. Acta Diabetol. 2010;47(3):193-9. doi: 10.1007/s00592-009-0109-4, PMID 19333547.

21. Imagawa A, Hanafusa T, Miyagawa J, Matsuzawa Y. A novel subtype of type 1 diabetes mellitus characterized by a rapid onset and an absence of diabetesrelated antibodies. Osaka IDDM Study Group. N Engl J Med. 2000;342(5):301-7. doi: 10.1056/NEJM200002033420501, PMID 10655528.

22. Imagawa $A$, Hanafusa $T$, Uchigata $Y$, Kanatsuka A, Kawasaki E, Kobayashi $T$, et al. Fulminant type 1 diabetes: A nationwide survey in Japan. Diabetes Care. 2003;26(8):2345-52. doi: 10.2337/diacare.26.8.2345, PMID 12882860.

23. Bach JF. Insulin-dependent diabetes mellitus as an autoimmune disease. Endocr Rev. 1994;15(4):516-42. doi: 10.1210/edrv-15-4-516, PMID 7988484.

24. Tisch R, McDevitt H. Insulin-dependent diabetes mellitus. Cell. 1996;85(3):291-7. doi: 10.1016/s0092-8674(00)81106-x, PMID 8616883.

25. Suwanwongse K, Shabarek N. Newly diagnosed diabetes mellitus, DKA, and COVID-19: Causality or coincidence? A report of three cases. J Med Virol. 2021;93(2):1150-3. doi: 10.1002/jmv.26339 [Epub:1150-3]. PMID 32706395.

26. Hyöty H. Viruses in type 1 diabetes. Pediatr Diabetes. 2016 [Suppl 22:56-64]; 17:56-64. doi: 10.1111/pedi.12370.

27. Apaolaza PS, Balcacean D, Zapardiel-Gonzalo J, Nelson G, Lenchik N, Akhbari P, et al. nPOD-Virus Group. Islet expression of type I interferon response sensors is associated with immune infiltration and viral infection in type 1 diabetes. Sci
Adv. 2021;7(9):eabd6527. doi: 10.1126/sciadv.abd6527, PMID 33627420.

28. Coppieters KT, Boettler T, Von Herrath M. Virus infections in type 1 diabetes. Cold Spring Harb Perspect Med. 2012;2(1):a007682. doi: 10.1101/cshperspect. a007682, PMID 22315719, PMCID PMC3253029.

29. Hanafusa T, Imagawa A. Fulminant type 1 diabetes: A novel clinical entity requiring special attention by all medical practitioners. Nat Clin Pract Endocrinol Metab. 2007;3(1):36-45; quiz 2p. doi: 10.1038/ncpendmet0351, PMID 17179928.

30. Goto A, TakahashiY, Kishimoto M, NakajimaY, Nakanishi K, Kajio H, et al. case of fulminant type 1 diabetes associated with significant elevation of mumps titers. Endocr J. 2008;55(3):561-4. doi: 10.1507/endocrj.K07E-126, PMID 18520103.

31. Akatsuka H, Yano Y, Gabazza EC, Morser J, Sasaki R, Suzuki T, et al. A case of fulminant type 1 diabetes with coxsackie B4 virus infection diagnosed by elevated serum levels of neutralizing antibody. Diabetes Res Clin Pract. 2009:84(3):e50-2. doi: 10.1016/j.diabres.2009.03.009. PMID 19362384

32. Hwang YC, Jeong IK, Chon S, Oh S, Ahn KJ, Chung HY, et al. Fulminant type 1 diabetes mellitus associated with acute hepatitis A. Diabet Med. 2010;27(3):366-7. doi: 10.1111/j.1464-5491.2010.02930.x, PMID 20536504.

33. Lönnrot M, Lynch KF, Elding Larsson $H$, Lernmark $\AA$, Rewers MJ, Törn $C$, et al. TEDDY Study Group. Respiratory infections are temporally associated with initiation of type 1 Diabetes autoimmunity: the TEDDY study. Diabetologia. 2017;60(10):1931-40. doi: 10.1007/s00125-017-4365-5, PMID 28770319.

34. Akatsuka H, Yano $Y$, Gabazza EC, et al. A case of fulminant type 1 Diabetes with coxsackie B4 virus infection diagnosed by elevated serum levels of neutralizing antibody. Diabetes Res Clin Pract. 2009; 84(3):50-52. doi: 10.1016/j. diabres.2009.03.009.

35. Li W, Moore MJ, Vasilieva N, Sui J, Wong SK, Berne MA, et al. Angiotensinconverting enzyme 2 is a functional receptor for the SARS coronavirus. Nature. 2003:426(6965):450-4. doi: 10.1038/nature02145, PMID 14647384.

36. Hamming I, Timens W, Bulthuis ML, Lely AT, Navis GJ, Van Goor H. Tissue distribution of ACE2 protein, the functional receptor for SARS coronavirus. A first step in understanding SARS pathogenesis. J Pathol. 2004;203(2):631-7. doi: 10.1002/path.1570, PMID 15141377.

37. Verdecchia P, Cavallini C, Spanevello A, Angeli F. The pivotal link between ACE2 deficiency and SARS-CoV-2 infection. Eur J Intern Med. 2020;76:14-20. doi: 10.1016/j.ejim.2020.04.037, PMID 32336612

38. Fignani D, Licata G, Brusco N, Nigi L, Grieco GE, Marselli L, et al. SARS-CoV-2 receptor angiotensin I-converting enzyme Type 2 (ACE2) is expressed in human pancreatic $\beta$-cells and in the human pancreas microvasculature. Front Endocrinol (Lausanne). 2020 Nov 13;11:596898. doi: 10.3389/fendo.2020.596898, PMID 33281748, PMCID PMC7691425.

39. Lang ZW, Zhang LJ, Zhang SJ, Meng X, Li JQ, Song CZ, et al. A clinicopathological study of three cases of severe acute respiratory syndrome (SARS). Pathology 2003;35(6):526-31. doi: 10.1080/00313020310001619118, PMID 14660106.

40. Shi X, Gong E, Gao D, Zhang B, Zheng J, Gao Z, et al. Severe acute respiratory syndrome associated coronavirus is detected in intestinal tissues of fatal cases. Am J Gastroenterol. 2005;100(1):169-76. doi: 10.1111/j.1572-0241.2005.40377.x, PMID 15654797.

41. Fignani D, Licata G, Brusco N, et al. SARS-CoV-2 receptor Angiotensin I-Converting Enzyme type 2 is expressed in human pancreatic islet $\beta$-cells and is upregulated by inflammatory stress. bioRxiv. 2020; 11:596898. doi: 10.3389/ fendo.2020.596898.

42. Sardu C, D'Onofrio N, Balestrieri ML, Barbieri M, Rizzo MR, Messina V, et al. Outcomes in patients with hyperglycemia affected by COVID-19: Can we do more on glycemic control? Diabetes Care. 2020;43(7):1408-15. doi: 10.2337/ dc20-0723, PMID 32430456.

43. Li J, Wang $X$, Chen J, Zuo $X$, Zhang H, Deng A. COVID-19 infection may cause ketosis and ketoacidosis. Diabetes Obes Metab. 2020;22(10):1935-41. doi 10.1111/dom.14057 [Epub:1935-41]. PMID 32314455.

44. Apicella M, Campopiano MC, Mantuano M, Mazoni L, Coppelli A, Del Prato S COVID-19 in people with diabetes: Understanding the reasons for worse outcomes. Lancet Diabetes Endocrinol. 2020 Sep;8(9):782-92. doi: 10.1016/ S2213-8587(20)30238-2 [Epub]. Erratum in: Lancet Diabetes Endocrinol. Erratum. 2020 Oct;8(10):e5 in: Lancet Diabetes Endocrinol. PMID: 32687793; PMC ID: PMC7367664. 2020 Nov;8(11):e6.

45. Steenkamp DW, Alexanian SM, McDonnell ME. Adult hyperglycemic crisis: A review and perspective. Curr Diab Rep. 2013;13(1):130-7. doi: 10.1007/s11892012-0342-z, PMID 23115048.

46. Palermo NE, Sadhu AR, McDonnell ME. Diabetic ketoacidosis in COVID-19: Unique concerns and considerations. J Clin Endocrinol Metab. 2020;105(8):2819-29. doi: 10.1210/clinem/dgaa360, PMID 32556147.

47. Dzygało K, Nowaczyk J, Szwilling A, Kowalska A. Increased frequency of severe diabetic ketoacidosis at type 1 diabetes onset among children during COVID-19 pandemic lockdown: An observational cohort study. Pediatr Endocrinol Diabetes Metab. 2020;26(4):167-75. doi: 10.5114/pedm.2020.101003, PMID 33554490.

Article History: Received: 20-08-2021; Revised: 29-09-2021; Accepted: 27-10-2021.

Cite this article: Annam P, Mandava K, Manda A, Kadam A, Thakur S. Covid-19 Induced Diabetes: Disclosing Truth behind the Potential Attention Seeker. J Young Pharm. 2021;13(4):352-5. 